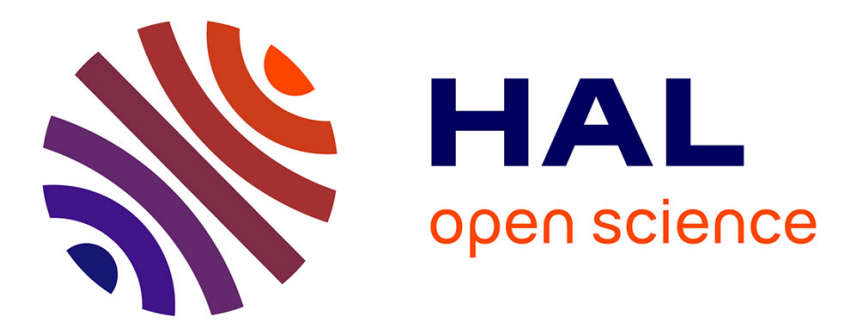

\title{
Frontal systems as mechanisms of fish aggregation
}

Alberto Baudena, Francesco d'Ovidio, Guido Boffetta, Silvia de Monte

\section{To cite this version:}

Alberto Baudena, Francesco d'Ovidio, Guido Boffetta, Silvia de Monte. Frontal systems as mechanisms of fish aggregation. CS-DC'15 World e-conference, Sep 2015, Tempe, United States. hal01291085

\section{HAL Id: hal-01291085 \\ https://hal.science/hal-01291085}

Submitted on 20 Mar 2016

HAL is a multi-disciplinary open access archive for the deposit and dissemination of scientific research documents, whether they are published or not. The documents may come from teaching and research institutions in France or abroad, or from public or private research centers.
L'archive ouverte pluridisciplinaire HAL, est destinée au dépôt et à la diffusion de documents scientifiques de niveau recherche, publiés ou non, émanant des établissements d'enseignement et de recherche français ou étrangers, des laboratoires publics ou privés. 


\title{
Frontal systems as mechanisms of fish aggregation
}

\author{
Alberto Baudena, Francesco d'Ovidio, Guido Boffetta, and Silvia De Monte \\ Locean - Université Pierre et Marie CURIE, \\ 4 Place Jussieu, 75005 Paris, France
}

\begin{abstract}
In contrast to terrestrial environments, the open ocean has a dynamics whose timescales overlap with the demography of the organisms it hosts. In particular, so called meso- and submeso-scale processes (1-100 km, days to weeks) have been shown to play a key role in structuring the distribution of phytoplankton, which form the large majority of the base of the trophic chain [2]. However, how the (sub)mesoscale turbulence affect higher trophic levels, which have typically swimming capabilities, is largely not known. Here we explore the capability of frontal system to aggregate swimming organisms (fish) by analyzing an idealised model of the stretching region which is often found in between mesoscale vortices. The rationale behind this approach is that an optimal niche for fish, defined in terms of physical properties or prey availability, may shrink with time under the coupled effect of stretching and diffusion. If the shrinking speed is less than the fish swimming capability, fish schools originally dispersed over a wide region may move inside a smaller area, and therefore increase their local density. The model is parameterised for one of the most abundant mesopelagic fish, the myctophid [4], particularly important in the Southern Ocean, using physical conditions representative of their environment.
\end{abstract}

\section{Introduction}

The oceans cover the $70 \%$ of the planet's surface, and are the place in which earth life was born and later has colonized the lands. Though that, terrestrial ecosystems are slightly different from oceanic ones [5]. The differences of marine environment are various: e.g., the phytoplankton, the major responsible of primary production in the oceans, have a biomass several-fold less than that of their dependents, the gravity is not of central importance, the new lineages tend to coexist with the older ones instead of replacing them etc. A marine life peculiar characteristic is that it has developed in an environment whose timescale dynamics overlap with the ones of its ecological processes.

In the past years, it has been shown that horizontal stirring at the (sub-) mesoscale (10-100s of $\mathrm{km}$, days to several weeks) play a central role in organizing the phytoplanktonic landscape along physical fronts [2]. These fronts enclose water patches with contrasted water properties ("fluid dynamical niches") long enough for types locally adapted to become predominant. Eventually, these 
Isoconcentration speed vs Effective fish speed

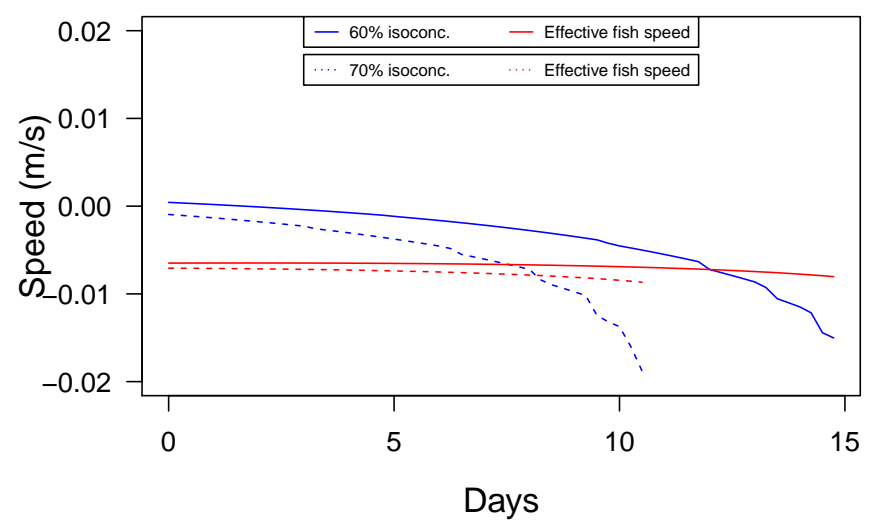

Fig.1

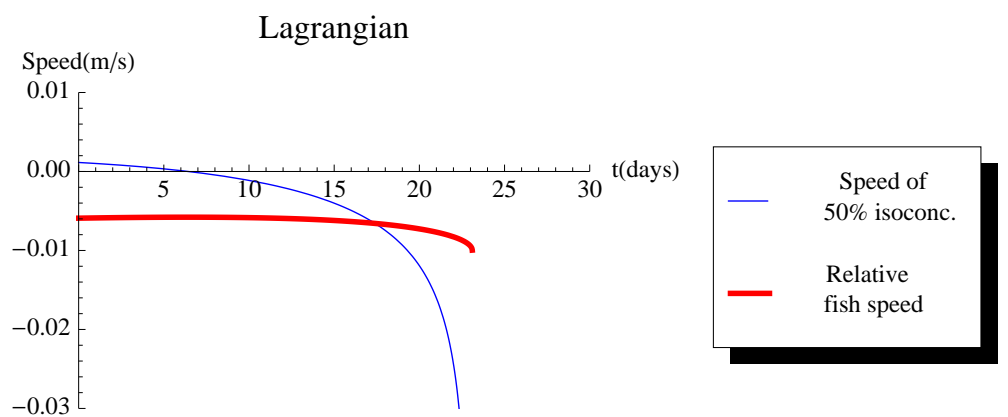

Fig.2

Fig. 1: and Fig. 2: Speed of the line of isoconcentration along the front (blue line) compared to the effective myctophid speed (order of magnitude). The first is considered positive if the patch is expanding, otherwise negative. Fig. 1 represents the speed of the isoconcentration of the cue (e.g., zooplankton concentration) at the $60 \%$ (continuos line) and $70 \%$ (dotted line) of the initial maximum value, while Fig. 2 refers to the $50 \%$. Fig. 1 is obtained with an Eulerian model, Fig. 2 with a Lagrangian one.

niches are stretched into thinner filaments that are mixed with waters far apart from their origin. This mechanism allows to build a highly diverse and widely distributed background of plankton types at the basin scale: this is a central issue in the dynamic and maintenance of planktonic biodiversity.

This dynamics has been described for primary producers. However, it is not clear how it affects the whole ecosystem, in particular because while plankton are passively advected, higher trophic elements can move actively. 
On the other end of the trophic chain, recent studies about the behavior of top predators have shown their tendency to fish in structures within intense (sub-) mesoscale activity, which correspond to waters which have supported planktonic blooms during spring [1], [3].

This suggest that (sub-) mesoscale features could have strong ecological implications because they can host high fish densities.

\section{Results and Discussion}

Here we study the evolution of an idealized patch of tracer (an unspecified cue for fish, for instance zooplankton concentration) initially distributed in a large area, exposed to a dynamic of diffusion and stretching, which is typically observed in the frontal regions visited by top predator during their foraging trips.

Starting assumption is that fish patches can react to the concentration of the cue by climbing the gradient. Exposed to diffusion and stirring dynamic, the initial patch of cue will tend to modify its shape and become smaller. If the fish are able to follow the gradient, they will tend to aggregate into a gradually smaller region.

It is useful to represent the surface currents in terms of phase space of a $2 \mathrm{D}$ dynamical system: in this way it is possible to represent a frontal system as a hyperbolic point, with a stable and an unstable manifold.

A first Lagrangian 1D approach is considered, and it is assumed, along the stable manifold, equilibrium between the diffusion and the stirring.

Along the front, the unstable manifold, we consider the speed as $u=\lambda x$, with $\lambda$ Lyapunov exponent and a initially normal distribution of the cue. It is possible to write an analytical expression for the position and the speed of the point of a specific concentration, that can be chosen as the boundary of the optimal niche.

The second approach considers the evolution of the concentration of a $2 D$ patch of cue, following the advection-diffusion equation:

$$
\frac{\partial C}{\partial t}+u \frac{\partial C}{\partial x}+v \frac{\partial C}{\partial y}=K_{H}\left(\frac{\partial^{2} C}{\partial x^{2}}+\frac{\partial^{2} C}{\partial y^{2}}\right)
$$

in which $u=\lambda x$ e $v=-\lambda y$.

We realized a numerical simulation of a $2 \mathrm{D}$ patch, using physical parameters representative of the Southern Ocean $\left(\lambda=0.05 d^{-1}, k=5 \mathrm{~m}^{2} \mathrm{~s}^{-1}\right)$, with a starting normal distribution of $\sigma_{x}=10 \mathrm{~km}$ and $\sigma_{y}=4 \mathrm{~km}, d x=d y=1000 \mathrm{~m}$, $d t=6 h$.

The simultaneous action of stirring and the diffusion compresses the cue toward the front and stretches it in the unstable direction, making the filament thinner and with lower concentrations.

Supposing that fish prefer to live in areas in which the cue is higher than a certain threshold (e.g. the $60 \%$ of the maximum value at $t=0$ ), we study the position and the velocity of the optimal niche boundaries, to verify if they are able to follow the gradient of with their swimming speed. In particular, we 
concentrate on the unstable manifold, where fish have more difficulties to go after the patch.

We define so an effective fish speed as:

$$
u_{e f f}=u_{M}-u_{C}(x)
$$

where $u_{M}$ is the average fish speed $\left(0,01 \frac{\mathrm{m}}{\mathrm{s}}\right)$ and $u_{C}(x)$ the velocity of the current in the point in which the fish are, that is so dependent from the position.

The value that we have chosen for the fish speed, are taken from swimming speed of the myctophid, a mesopelagic fish which constitute a large component of the diet of many predators of the open ocean [4]. As it is possible to see from Fig. 1 and 2 we found that the isoconcentration lines speed are compatible with the myctophids one, suggesting that the fish may be able to follow the optimal niche for about ten days, increasing so their local density.

\section{Scientific Validation}

This paper has been unanimously validated in a collaborative review mode with the following reviewers:

- Francesco Nencioli, Plymouth Marine Laboratory

- Yohav Lehah, Department of Earth and Planetary Sciences

\section{References}

1. Cédric Cotté, Francesco d'Ovidio, Anne-Cécile Dragon, Christophe Guinet, and Marina Lévy. Flexible preference of southern elephant seals for distinct mesoscale features within the antarctic circumpolar current. Progress in Oceanography, 131(0):46 $-58,2015$.

2. Francesco d'Ovidio, Silvia De Monte, Séverine Alvain, Yves Dandonneau, and Marina Lévy. Fluid dynamical niches of phytoplankton types. Proceedings of the National Academy of Sciences, 107(43):18366-18370, October 2010.

3. Olav R. Godø, Annette Samuelsen, Gavin J. Macaulay, Ruben Patel, Solfrid Sœtre Hjøllo, John Horne, Stein Kaartvedt, and Johnny A. Johannessen. Mesoscale eddies are oases for higher trophic marine life. PLoS ONE, 7(1):e30161, 012012.

4. Xabier Irigoien, Thor A Klevjer, Anders Røstad, U Martinez, G Boyra, JL Acuña, A Bode, F Echevarria, JI Gonzalez-Gordillo, Santiago Hernandez-Leon, et al. Large mesopelagic fishes biomass and trophic efficiency in the open ocean. Nature communications, 5, 2014.

5. Victor Smetacek. Making sense of ocean biota: How evolution and biodiversity of land organisms differ from that of the plankton. Journal of Biosciences, 37(4):589 $607,2012$. 